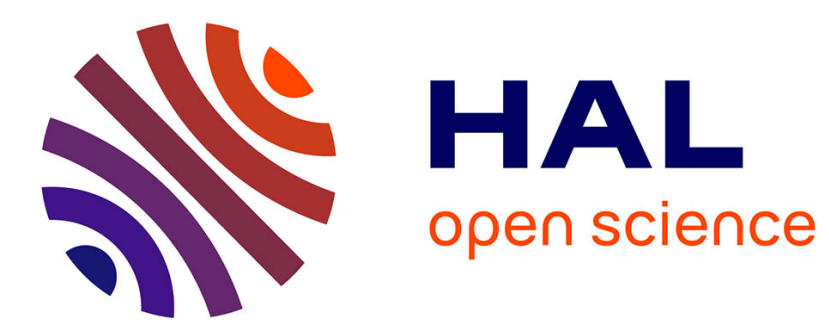

\title{
From waste to kwaste: on the Blue Economy in terms of knowledge flow
}

Idriss J. Aberkane

\section{To cite this version:}

Idriss J. Aberkane. From waste to kwaste: on the Blue Economy in terms of knowledge flow. CS-DC'15 World e-conference, Sep 2015, Tempe, United States. hal-01291106

\section{HAL Id: hal-01291106 https://hal.science/hal-01291106}

Submitted on 20 Mar 2016

HAL is a multi-disciplinary open access archive for the deposit and dissemination of scientific research documents, whether they are published or not. The documents may come from teaching and research institutions in France or abroad, or from public or private research centers.
L'archive ouverte pluridisciplinaire HAL, est destinée au dépôt et à la diffusion de documents scientifiques de niveau recherche, publiés ou non, émanant des établissements d'enseignement et de recherche français ou étrangers, des laboratoires publics ou privés. 


\title{
From waste to kwaste: on the Blue Economy in terms of knowledge flow
}

\author{
Idriss J. Aberkane \\ Unesco-Unitwin Complex Systems Digital Campus 7 rue René Descartes F-67000 \\ Strasbourg, France \\ Centre de Recherche en Gestion, Ecole Polytechnique Bâtiment Enta 828 Boulevard \\ des Maréchaux 91762 Palaiseau Cedex, France \\ 3 \\ Kozmetsky Global Collaboratory Stanford University Kozmetsky Family Center 224 \\ Panama Street (Nora Suppes Hall), Suite 104 Stanford University Stanford, CA \\ 94305-4110, USA \\ idriss.aberkane@polytechnique.edu
}

\begin{abstract}
Introduced by Gunter Pauli, the Blue Economy, namely bio-inspired industrial ecology or self-profitable circular economy, is a remarkable example of the way the knowledge flow can fundamentally alter micro, meso and macroeconomics, and be converted into cash flow. Its reception is also a case of limited rationality in management and economics, and of resistance to change in general. Here I simplify the Blue Economy to the following equation: waste + knowledge $=$ asset. I then explore the implications of this equation in terms of venture capitalism (microeconomics) accounting (micro-mesoeconomics) and in terms of GDP (macroeconomics). I finally discuss its possible impact on politico-economic decision-making and its clear continuity with the knowledge economy. One fertile question thus arises: what could be the micro-mesomacro-economic stygmergies of the Blue Economy?
\end{abstract}

keywords: Blue Economy, biomimicry, knowledge flow, synergy, industrial ecology, sustainable development, economy of knowledge, stygmergy, mesoeconomics, self-organisation

\section{Introduction}

Currently, the Blue Economy may be the most sophisticated biologically-inspired economic theory, and at the same time the most practical. It is a paradigm considering that waste-free production can be more profitable than current industrial production. Contrary to the so-called Green Economy, it does not consider that the solving of pollution will inevitably impede growth, but rather that there is a paradigm shift to transcend the conflict of interest between growth and sustainable development. This paradigm shift is fundamentally bio-inspired and synergistic, and may be summed up in the sentence 
We should not ask nature to produce like our economy, we should ask our economy to produce like nature.

\section{Bio-inspired economics}

Nature has poorly been studied as an economic system in its totality, rather than in the limited consideration of its tradable outputs (eg. fisheries), but were it investigated as such, its ingenuity and multiscale optimality would surely deserve several Nobel prizes, and expand the field of bioeconomics. In Nature, wastes are an exception, and they exist only at the micro-ecologic scale, for the ecosphere, globally, is in homeostasis, and does not accumulate any particular chemical. On the other hand, our economic systems are not in homeostasis, and do accumulate various products. The point is that for anything that Nature produces, there always ends up to be a demand.

\section{Macroeconomic optimality of Nature}

For anything that the ecosphere currently produces, there is a demand from the ecosphere itself

Let us note however that this optimality is global (macroeconomic) for it does not always apply at the ecosystem level. It is also time-dependent, at equilibrium precisely; as we will see, the ecosphere may have been seen to have produced wastes in the past. In human systems on the other hand, most value chains end up producing wastes, which are not an exception but the rule of our industrial production, and which accumulate globally. We are probably the only species to produce things that nobody wants. Wastes can indeed be defined as products for which there is a negative demand, products that one would accept only with a payment. Nuclear wastes clearly fall under this category, so do persistant organic pollutants (pop) or even, intriguingly enough, most of the world's output of used ground coffee today, although this is rapidly changing.

\section{Macroeconomic suboptimality of Humanity}

Humanity produces things for which their is a negative demand, at both the microeconomic (local) and macroeconomic (global) levels

If we were producing any of our goods and services in the circular way of nature indeed, there would be no waste. This observation has been made by many such as Ellen MacArthur, Janine Benyus, Fritjof Capra and of course Gunter Pauli. 
In Nature, macroeconomic optimality is the rule; in Humanity, it is the exception. Nature achieves economic optimality faster than Humanity, at any scale. Nature is the best representation of the Invisible Hand, before human-made economic systems.

\section{Trial and Error v. Planification}

Man is more risk-advert than Nature. Nature's route to market optimisation is multiscale trial-and-error. Man's route to market optimisation is planification at the micro, meso and early macroscopic levels: individuals plan their decisions, enterprises plan their decisions, states plan their decisions, and so do central banks. Nature

does not plan, it tries, regrets not the past, fears not the future. Man's fear of the future and regret of the past is the essence of Humanity's multi-level suboptimalities.

Sustainable Development is essentially a Man-made answer to Man-made problems. Without Humanity, there would be no sustainable development, for ecosystems are fundamentally converging to sustainability. Better, any ecosystem suboptimality is transformative in Nature. It could be so of Man-made markets, and this scientific ambition founds biologically-inspired econonomics.

How about the kinetic and the thermodynamic of a transition between a linear and a circular (bio-inspired) economy however? The contribution of Gunter Pauli regards both the equilibrium state, for which MacArthur has already well argued that it is in favor of the circular economy, and the activation energy or barrier to entry for a Blue Economy retrofitting. This article studies the latter: the micro, meso and macroeconomic interests of a conversion to the Blue Economy, and their cognitive barriers among others. It also studies both its possible stygmergies from the perspective of a "Technopolis Phenomenon": Silicon Valley indeed, the best known contemporary technopolis, self-organized through entrepreneurial stygmergies, that is, the phenomenon of constructive peer-inspiration. Can't a global conversion from linear to selfprofitable circular economic go the same way, especially more so with the network effects allowed by both crowdsourcing and the Internet in general?

\section{Why Blue Economy?}

Pauli named the "Blue Economy" not only in reference to the oceans, but primarily in the idea that "blue is the new green", in the sense that the blue economy, unlike the green one, must be profitable in itself, because Nature is both a waste-free industrial system and still a cheaper, leaner, more effective one than ours. It is thus not ridiculous to consider that pollution-free production could be more competitive than the current production, without subsidies or even externality taxes.

If Pauli defined "blue" as simply "green 2.0" I may add another metaphor to understand the origin of this "blue" name. Has Nature produced waste in the past, or is its current state of globally waste-free ecosystem production an attribute of even the earliest ecosystems? Nature has indeed produced some wastes in the past, the most dreadful of all being... gaseous dioxygen. Dioxygen did provoke a relative extinction 
of biodiversity that was greater, by several orders of magnitude indeed, than the one that the very simultaneous release of absolutely all man-made pollutants would ever cause. The Great Oxygenation as it is referred to in geology was, in relative biodiversity, the greatest extinction of all the biosphere. Yet, it is thanks to oxygen that planet Earth is this "pale blue dot" we know of, and is green as well. If the very worst waste of natural history could be turned into a blessing, ours, even the most dreadful, are just trivial in comparison.

\section{Transformative nature of wastes}

In Nature, wastes induce forward-leaning transformation. In Humanity, they induce backward-leaning conservation.

If we consider that human societies are antifragile (in the sense of Taleb 2012) then adding a constraint to them does not necessarily imply impeding their development; one could rather verify the opposite throughout history, an observation that was at the heart of Leibniz's optimistic theodicy. One such case of industrial anti fragility was the abolition of slavery during the US Civil War: far from being a handicap to the Union, it ended up an economic blessing, because it accelerated the industrial adoption of the steam engine on the short term, and the advent of a consumer economy on the long term.

One usually attributes to Schopenhauer the three stages of the adoption of a revolution in Human history, be it scientific, philosophical, technological, political or moral:

"Schopenhauer's" three stages of revolutionary adoption

first it is considered ridiculous, then it is considered dangerous, and then it is considered self-evident.

Gandhi defined a similar dynamic: "first they ignore you, then they laugh at you, then they fight you, then you win". That any revolutionary idea, such as the founding principle of quantum mechanics, the marginal reproduction of mature neurons or the existence of a cerebral lymphatic system, among many others must first be considered ridiculous and then dangerous also explains the well-known suboptimality of academic peer-review, which is but peer-pressure in essence, and thus fundamentally inimical to paradigm shifts, normative in nature.

The Blue Economy is surely crossing the three stages of revolutionary adoptions. If the abolition of slavery was a moral, industrial, political and intellectual challenge of the 19th century, and the abolition of apartheid of the 20th century, the abolition of pollution should be the one of the 21 st century. Probably the only way to achieve it is to demonstrate that this Pareto optimum can also be a Nash equilibrium. What allows for such a dramatic phase transition is knowledge economy: assuming one demonstrates that the game of prosperity has much different rules than the ones we took for granted, one could establish a demonstration that pollution zero is not only Paretooptimal but also a Nash equilibrium. I believe the Blue Economy is the most promising paradigm in this direction. It shows that prosperity is a game with dynamic rules, and I may formulate it as the simplest possible equation: 


$$
\text { waste }+ \text { knowledge }=\text { asset }
$$

If in any economic game, holding waste were equivalent to a loss, holding waste plus the adequate knowledge could be a win. The knowledge flow can dramatically alter the dynamic of economic games regarding wastes, at the microeconomic level of individuals or small groups holding wastes, at the mesoeconomic level of enterprises, for which the knowledge flow could alter their accounting in the non-linear way of turning liabilities into assets, and finally at the macroeconomic level, where states could consider wastes as an opportunity for growth.

\section{In terms of knowledge flow}

What if sustainable development was a proper subfield of the knowledge economy? One could define sustainable development as the art of not trivially wasting resources today, that could be better used tomorrow. Biomimicry is thus a perfect example of sustainable development, as it consists of considering nature not a source of raw material but a source of knowledge. The Blue Economy posits, in the same way, a certain "knowledge panacea doctrine". There is surely more than a synergy between nooconomics (the knowledge economy) and the Blue Economy, the latter is rather an industrial and managerial subfield of the former.

One should first consider the Blue Economy in microeconomic terms. I have reminded of the conservative cognitive bias towards the adoption of revolutions, and it has a decisive impact on the individual knowledge flow. If we were to consider industrial decision-makers as purely rational agents of course, we would expect them to convert all the useful knowledge available to them into action, and in particular that all the knowledge relevant to profitable waste transformation be used to that end. Individual behaviour is not that rational however. First, for a given knowledge to be adopted, it needs to resonate with the existing paradigm of the receiver, otherwise, no matter how well it is demonstrated, it will be rejected.

Of the most significant cognitive biases I should underline in the study of the Blue Economy in terms of knowledge flow is the bias of conformity. When faced with the dilemma of adopting the truth and leaving one's comfort zone or staying within one's comfort zone and rejecting the truth, most human beings will choose the later. An evolutionary reason that is often invoked to explain this phenomenon is that we, contemporary humans, are mostly the descendent of the weak-minded humans who survived by preferring to remain in their tribe and reject the truth every time they were faced with the dilemma. The others have died. For, between leaving the group and adopting the truth and leaving the truth and remaining in the group, be it in the savannah or during the Ice Age, the latter meant survival, and the former quasi-certain death. Although the adoption of disruptive knowledge is not really equivalent to death anymore, our brain has evolved to discourage it as much as possible, as long as it goes 
against in-group favoritism. Hence the following strong proposition that the Blue Economy should be "won in the middle":

\section{Mesoscopic synergy of the Blue Economy}

The adoption dynamic of the Blue Economy, in terms of knowledge flow, does not favor the microscopic but rather the mesoscopic scale. The Blue Economy will be all the more successful as it targets neither individuals (micro) nor nations or even cities (macro) but groups and groups of groups (meso).

It is a testable hypothesis that the adoption dynamic of the Blue Economy should give a premium to the mesoscopic scale, for it is the scale in which the all-or-none mechanism for the adoption of disruptive knowledge could prove the least disruptive. Groups, and groups of groups - not individuals - should be the targets.

If knowledge holders are to be modelled as biased maximising agents, as in regular economics, then one should study the social conditions under which they will be willing to maximise their knowledge flow. For in nooconomics (the economy of knowledge), the willingness to acquire knowledge is the very first bottleneck of knowledge logistics (applied noodynamics). From a macroeconomic perspective, one should observe that statement (7) implies that economies producing a lot of waste and at the same time a lot of knowledge could most benefit from the Blue Economy in terms of GDP. This alone of course, could explain the political interest of China for the field. The general statement is that the best way to manage a waste is not to bury it deep in either dirt or water, but in knowledge.

At the transition between the meso and macroeconomics of the synergy between waste and knowledge many business models could be developed, as, for example lines of services in the accounting and auditing businesses, because if statement (7) becomes a standard industrial observation, then knowledge and externalities should be accounted for in a completely different manner in financial terms. Maybe generally accepted accounting practices could also very well benefit from a retrofitting in the Blue Economy. From the high mescoscopic point of view of multinational firms, this would be a novel, readily available though untapped well of profitability, and boasting a genuinely operational "Blue" label (which could become the trade of ad hoc rating agencies) could end up a critical success factor for any publicly-traded company. This is exactly the kind of mesoscopic effect that the Blue Economy should seek. From the lowest macroeconomic level then, that of national or regional administrations, one could observe that such a behaviour would encourage corporations to internalise their externalities as systematically as possible. Why externalise wastes indeed if these liabilities, once blended with the appropriate knowledge, end up being assets? These possible mesoscopic behaviours seem rather intuitive, but they are merely the outline of the more thorough economic model one should develop to systematise the synergy between nooconomics and industrial ecology. 


\section{Conclusion: in terms of stygmergies}

Peer pressure is a normative phenomenon. One of its emerging effects is social inertia, but also social stabilisation. Thus at the beginning of a revolution, peer-pressure is what encourages an idea to be considered ridiculous and dangerous, but then it is also what helps revolutions to move towards self-evidence. There is a tipping point between conservative peer-pressure and innovative peer-pressure.

A stygmergy is the self-organisation of a synergy, for example an optimal collective pathway, usually at the mesoscopic scale (that of groups and groups of groups) through various forms of reinforcements. The self-organised stabilisation of the shortest pathway through pheromone signalling in anthills is the textbook example of a stygmergy. Economic systems typically display stygmergies as well, be they destructive (like a bank run), constructive, or neutral. The history of Silicon Valley was typically one of stygmergies, based on constructive peer pressure, e.g. "if I succeeded, why would you not". The opposite of course, destructive peer-pressure would be "if I failed, why would you succeed?".

The dynamic adoption of the Blue Economy poses the question of its entrepreneurial stygmergies, especially at the mesoscopic scale (that of small and medium enterprises). If the emergence of Silicon Valley was a typical "technopolis phenomenon" by which the enthusiasm of novel project holders self-organised along the fresh trails of earlier successful entrepreneurs, could there be an identical "Blue Technopolis Phenomenon"? How would the man-hill of blue entrepreneurs self-organise? Would it reach homeostasis, expand - by converting new entrepreneurs - or collapse?

Here I opinionated how the knowledge flow can alter the meso-economic dynamic of Man's interaction with wastes, along the general idea that, in the 21 st century, Man will learn to bury not their wastes in either dirt or water but in knowledge. If waste+ knowledge $=$ asset (proposition 7) then the entire interest of the Blue Economy is to catalyse the conversion of wastes into "kwastes", that is, appropriately paired bits of wastes and bits of knowledge. Surely crowdsourcing could benefit such a global catalysis, especially considering that human knowledge is intrinsically collegial. The crowdsourcing of the collectivisation of knowledge (Wikipedia being the clearest example of it) can encourage stygmergies and the emergence of a common sense. Should an equivalent "kwaste" platform be established, to maximise the interaction between wastes and knowledge (and appropriately called "Wikiwaste")? Nature's way to deal with wastes is to surround them with trial-and-error. Man's way of dealing with wastes should be to surround them with knowledge. As the No Free Lunch theorem establishes that there is no more efficient optimisation strategy than a random search over all types of optimisation problems, maybe trial and error is actually the very best way for the ecosphere to incorporate novel molecules into its many cycles. Should it also be that of Man? 


\section{References}

1. Benton, D., Hazell, J., and Hill, J. (2015). The Guide to the Circular Economy: Capturing Value and Managing Material Risk (DoSustainability).

2. Benyus, J.M. (2009a). Biomimicry (HarperCollins).

3. Benyus, J.M. (2009b). Biomimicry (HarperCollins).

4. Benyus, J.M., and Barberis, J.C. (1992a). The Secret Language and Remarkable Behavior of Animals (Black Dog \& Leventhal Publishers).

5. Benyus, J.M., and Barberis, J.C. (1992b). The Secret Language and Remarkable Behavior of Animals (Black Dog \& Leventhal Publishers).

6. Benyus, J., and Pauli, G. (2009a). Nature's 100 Best: World-Changing Innovations Inspired by Nature (Chelsea Green Publishing Company).

7. Benyus, J., and Pauli, G. (2009b). Nature's 100 Best: World-Changing Innovations Inspired by Nature (Chelsea Green Publishing Company).

8. Capra, F., and Pauli, G. (1996). The challenge. F Capra and G Pauli, New Delhi: Response.

9. Capra, F., and Pauli, G.A. (1995). Steering business toward sustainability (United Nations University Press Tokyo).

10. Clark, C.W. (2010). Mathematical Bioeconomics: The Mathematics of Conservation (John Wiley \& Sons).

11. Corning, P. (2010). Holistic Darwinism: Synergy, Cybernetics, and the Bioeconomics of Evolution (University of Chicago Press).

12. Ellen MacArthur Foundation (Cowes, I. of W., and Company, M.\& (2012). Towards the Circular Economy (Ellen MacArthur Foundation).

13. Georgescu-Roegen, N., Mayumi, K., and Gowdy, J.M. (1999). Bioeconomics and Sustainability: Essays in Honor of Nicholas Georgescu-Roegen (Edward Elgar).

14. Keller, R.P., Lodge, D.M., and Lewis, M.A. (2009a). Bioeconomics of Invasive Species:Integrating Ecology, Economics, Policy, and Management (Oxford University Press, USA).

15. Keller, R.P., Lodge, D.M., and Lewis, M.A. (2009b). Bioeconomics of Invasive Species:Integrating Ecology, Economics, Policy, and Management (Oxford University Press, USA).

16. Kopnina, H., and Blewitt, J. (2014). Sustainable Business: Key Issues (Taylor \& Francis).

17. Lovins, A., Braungart, M., and Foundation, E.M.A. (2014). A New Dynamic - Effective Business in a Circular Economy (Ellen MacArthur Foundation Publishing).

18. Mathews, J.A., and Tan, H. (2011). Progress toward a circular economy in China. Journal of Industrial Ecology 15, 435-457.

19. Moxnes, E. (1998). Not only the tragedy of the commons: misperceptions of bioeconomics. Management Science 44, 1234-1248.

20. Nabudere, P.D.W. (2013). From Agriculture to Agricology: Towards a Glocal Circular Economy (STE Publishers).

21. Ning, D. (2001). Cleaner Production, Eco-industry and Circular Economy [J]. Research of Environmental Sciences 6, 000.

22. Pauli, G. (1995). Industrial clusters of the twenty-first century. In Steering Business Toward Sustainability, (United Nations University Press Tokyo),

23. Pauli, G. (1996). Breakthroughs: what business can offer society (Epsilon Press Limited).

24. Pauli, G. (1997). Zero emissions: the ultimate goal of cleaner production. Journal of Cleaner Production 5, 109-113.

25. Pauli, G. (1998a). Technology forecasting and assessment: The case of zero emissions. Technological Forecasting and Social Change 58, 53-62.

26. Pauli, G.A. (1987). Services: the driving force of the economy (Pergamon Pr).

27. Pauli, G.A. (1998b). Upsizing (Greenleaf). 
28. Pauli, G.A. (2010). The blue economy: 10 years, 100 innovations, 100 million jobs (Paradigm Publications).

29. Rougerie, J., Civard-Racinais, A., and Fuchs, A. (2010). De Vingt mille lieues sous les mers à SeaOrbiter (Democratic books).

30. Slavid, R. (2009). Extreme architecture (Laurence King).

31. Yuan, Z., Bi, J., and Moriguichi, Y. (2006). The circular economy: A new development strategy in China. Journal of Industrial Ecology 10, 4-8.

32. Zhou, Q. (2011). Applied Economics, Business and Development: International Symposium, ISAEBD 2011, Dalian, China, August 6-7, 2011, Proceedings (Springer). 